\title{
Protective Metal Oxide Coatings on Zinc-sulfide-based Phosphors and their Cathodoluminescence Properties
}

\author{
Sung-Il Oh, Hyo-Sung Lee, Kwang-Bok Kim, ${ }^{\dagger}$ and Jun-Gill Kang* \\ Department of Chemistry, Chungnam National University, Daejeon 305-764, Korea. *E-mail: jgkang@cnu.ac.kr \\ ${ }^{\dagger}$ Kumho Electric Inc., 64-1, Bongmyung-Ri, Namsa-Myun, Youngin, Gyeonggi-Do 449-883, Korea \\ Received April 20, 2010, Accepted October 19, 2010
}

\begin{abstract}
We investigated the high-excitation voltage cathodoluminescence $(\mathrm{CL})$ performance of blue light-emitting $(\mathrm{ZnS}$ : $\mathrm{Ag}, \mathrm{Al}, \mathrm{Cl})$ and green light-emitting $(\mathrm{ZnS}: \mathrm{Cu}, \mathrm{Al})$ phosphors coated with metal oxides $\left(\mathrm{SiO}_{2}, \mathrm{Al}_{2} \mathrm{O}_{3}\right.$, and $\left.\mathrm{MgO}\right)$. Hydrolysis of the metal oxide precursors tetraethoxysilane, aluminum isopropoxide, and magnesium nitrate, with subsequent heat annealing at $400{ }^{\circ} \mathrm{C}$, produced $\mathrm{SiO}_{2}$ nanoparticles, an $\mathrm{Al}_{2} \mathrm{O}_{3}$ thin film, and $\mathrm{MgO}$ scale-type film, respectively, on the surface of the phosphors. Effects of the phosphor surface coatings on CL intensities and aging behavior of the phosphors were assessed using an accelerating voltage of $12 \mathrm{kV}$. The $\mathrm{MgO}$ thick film coverage exhibited less reduction in initial CL intensity and was most effective in improving aging degradation. Phosphors treated with a low concentration of magnesium nitrate maintained their initial CL intensities without aging degradation for $2000 \mathrm{~s}$. In contrast, the $\mathrm{SiO}_{2}$ and the $\mathrm{Al}_{2} \mathrm{O}_{3}$ coverages were ineffective in improving aging degradation.
\end{abstract}

Key Words: ZnS:Ag,Al,Cl, ZnS:Cu,Al, Metal oxide coating, Cathodoluminescence, Aging degradation

\section{Introduction}

Field emission display (FED) shows great potential for use in a flat panel display manufacturing. The FED operating mechanism is very similar to that of a conventional cathode ray tube (CRT) display, i.e. the phosphors are bombarded by streams of electrons. However, FED uses an array of emitters directly opposite the color pixels instead of a single source used in CRT display. FED combines the advantage of CRT displays (e.g., high resolution, fast response time, wide viewing angles, and high contrast levels) with the flatness and the thinness of plasma display panel (PDP) and liquid crystal display (LED). Currently, blue and green zinc sulfide-based phosphors ( $\mathrm{ZnS}$; P22B and $\mathrm{P} 22 \mathrm{G})$, and red yttrium oxysulfide-based $\left(\mathrm{Y}_{2} \mathrm{O}_{3} \mathrm{~S}: \mathrm{Eu}^{3+} ; \mathrm{P} 22 \mathrm{R}\right)$ phosphors are used in FED technology. When these phosphors are irradiated with an electron beam, they experience fast degradation, decreasing the luminous efficiency, and generate harmful gases such as $\mathrm{SO}_{\mathrm{x}}{ }^{1,2}$ To avoid these problems, phosphor surfaces have been coated with metal oxides, such as $\mathrm{SiO}_{2}, \mathrm{MgO}$, $\mathrm{ZnO}, \mathrm{Al}_{2} \mathrm{O}_{3}$ and $\mathrm{In}_{2} \mathrm{O}_{3}{ }^{3-10}$ Intrinsic luminous efficiencies and aging effects of metal-oxide-coated phosphors have been investigated for accelerating voltages lower than $10 \mathrm{kV}$.

Carbon nanotubes (CNT) are being investigated as electron field emitters for FED ${ }^{11-16}$ and flat lighting device. ${ }^{17-19}$ For a CNT-FED, the applied voltage should be higher than $10 \mathrm{kV}$ to obtain reliable luminance. ${ }^{20-21}$ For a green $\mathrm{P} 22 \mathrm{G}$ phosphor, the luminance decreased suddenly at $1.3 \mathrm{kV}$ when the space distance between the CNT emitter and the phosphor was $0.2 \mathrm{~mm} .{ }^{22}$ For a lighting device with a CNT emitter, phosphors fabricated on anode side must be tolerant of an accelerating electron beam higher than $10 \mathrm{kV}$. We coated blue $\mathrm{P} 22 \mathrm{~B}$ and green $\mathrm{P} 22 \mathrm{G}$ phosphors with $\mathrm{SiO}_{2}, \mathrm{Al}_{2} \mathrm{O}_{3}$ and $\mathrm{MgO}$ using various methods for testing in a CNT lighting device. The effect on cathodoluminescence (CL) from coating the phosphors was investigated as a function of an accelerating voltage, particularly focusing on degradation behavior under CL excitation.

\section{Experimental}

Blue light-emitting P22B and green light-emitting P22G phosphors were purchased from IRICO Group Corp. (Beijing, China). The $\mathrm{SiO}_{2}$ coating process used tetraethoxysilane (TEOS; 98\%, Sigma-Aldrich, St. Louis, MO, USA) as the precursor material. Varying amounts (by percent weight of the phosphor) of TEOS were dissolved in $6 \mathrm{~mL}$ of a $1: 1$ solvent mixture of ethanol and water. Phosphor powder $(1.0 \mathrm{~g})$ was then added to the precursor solution. After adjusting the $\mathrm{pH}$ to 9 using diluted $\mathrm{NH}_{4} \mathrm{OH}$, the mixture was refluxed at $80^{\circ} \mathrm{C}$ for $2 \mathrm{~h}$. The slurry was dried and then heat-treated in a box furnace at $400{ }^{\circ} \mathrm{C}$ for $3 \mathrm{~h}$.

Two precursors, aluminum nitrate hexahydrate (AN; 99\%, Sigma-Aldrich) and aluminium isopropoxide (AI; 99 \%, SigmaAldrich), were used to create $\mathrm{Al}_{2} \mathrm{O}_{3}$-coated phosphors. Varying amounts (by percent weight of the phosphor) of AN were dissolved in $50 \mathrm{~mL}$ of $\mathrm{H}_{2} \mathrm{O}$, and $1 \mathrm{~g}$ of phosphor powder was dispersed in each solution. After adjusting the $\mathrm{pH}$ to $11 \mathrm{using}$ dilute $\mathrm{NH}_{4} \mathrm{OH}$, the mixture was stirred at $40^{\circ} \mathrm{C}$ for $1 \mathrm{~h}$. The resulting mixture was dried and then heat-treated in a box furnace at $400{ }^{\circ} \mathrm{C}$ for $3 \mathrm{~h}$. Similarly, varying amounts (by percent weight of the phosphor) of AI were dissolved in $50 \mathrm{~mL}^{\circ} \mathrm{H}_{2} \mathrm{O}$, and $1 \mathrm{~g}$ of phosphor powder was dispersed in each solution. The mixture was heated at $90{ }^{\circ} \mathrm{C}$ for $24 \mathrm{~h}$ with continuous stirring. After cooling to room temperature and adjusting the $\mathrm{pH}$ to $4.5 \mathrm{using}$ dilute $\mathrm{HNO}_{3}$, the mixture was ultrasonicated until becoming viscous, then dried and annealed at $400{ }^{\circ} \mathrm{C}$ for $3 \mathrm{~h}$ in a box furnace. Basic $\mathrm{pH}$ condition and ultrasonic treatment resulted in a highly uniform, thin $\mathrm{Al}_{2} \mathrm{O}_{3}$ film. MgO-coated phosphors, using magnesium nitrate hexahydrate ( $99 \%$, Sigma-Aldrich) as a precursor, were created using the same process as described for AN.

Phase information and surface morphology of coated phosphors were characterized by field emission scanning electron microscopy (FE-SEM) and energy dispersive spectroscopy (EDS). FE-SEM micrographs and EDS spectra were acquired using a JSM-7000F FE-SEM (JEOL, Tokyo, Japan). 
For the fabrication of CL device, a viscous binder was prepared by dissolving ethyl cellulose ( $5 \mathrm{wt} \%$ ) in $\alpha$-terpineol, heating at $70-80^{\circ} \mathrm{C}$ for $2 \mathrm{~h}$, and then phosphor powders were mixed with the binder at 10:6 wt ratio. Each mixture was casted on a glass using a YP-450HP printer (Yuil System, Seoul, Korea). Castings were annealed by multi-step heating, going from $280{ }^{\circ} \mathrm{C}$ for $2 \mathrm{~h}$ to $460{ }^{\circ} \mathrm{C}$ for $1 \mathrm{~h}$. CL intensity was measured using a BM-7 Luminance Colorimeter (Topcon, Tokyo, Japan) under high vacuum $\left(5.0 \times 10^{-6}\right.$ torr $)$ with an electrongun (PSI, Seoul, Korea).

\section{Results and Discussion}

Surface morphology. Figure 1 shows the surface morphologies of uncoated and $\mathrm{SiO}_{2}$-coated blue and green phosphors. The surface of uncoated blue phosphor was smooth and clean, but some particles adhered to the uncoated green phosphors. After treatment with $1 \mathrm{wt} \%$ of TEOS precursor, blue phosphor surfaces were covered with $\mathrm{SiO}_{2}$ nanoparticles (the sizes of the isolated particles are shorter than $\sim 100 \mathrm{~nm}$ ), and the density increased with increasing amounts of the TEOS precursor (Figure 1a). Green phosphor surfaces were not completely covered with $\mathrm{SiO}_{2}$ nanoparticles below a $10 \mathrm{wt} \%$ TEOS concentration (Figure 1b). EDS was used to analyze the surface element for all blue and green phosphors treated with $10 \mathrm{wt} \%$ precursor solutions. As shown in Figure 2, $\mathrm{Si}$ and $\mathrm{O}$ peaks in the surface concentration were observed at 2.5 and $0.5 \mathrm{keV}$, respectively. The results of the EDS analyses are listed in Table 1.

Blue phosphor surfaces were uniformly covered with a thin, transparent $\mathrm{Al}_{2} \mathrm{O}_{3}$ thin film when treated with a $10 \mathrm{wt} \% \mathrm{AN}$ precursor (Figure $3 \mathrm{a}$ ), while green phosphor surfaces had only a few isolated $\mathrm{Al}_{2} \mathrm{O}_{3}$ islands (Figure $3 \mathrm{~b}$ ). Even at the highest precursor concentrations, only a small portion of green phosphor surfaces were covered by $\mathrm{Al}_{2} \mathrm{O}_{3}$ islands. Use of $\mathrm{AI}$ as a precursor resulted in both blue and green phosphor surfaces being fully coated with an $\mathrm{Al}_{2} \mathrm{O}_{3}$ thin film (Figure 4). Use of ultrasonic irradiation during solution processing produced a more uniform surface $\mathrm{Al}_{2} \mathrm{O}_{3}$ thin film even with low concentrations of $\mathrm{AI}$.

Some portion of both blue and green phosphor surfaces were covered with $\mathrm{MgO}$ scale-type films after treatment with a $1 \mathrm{wt} \%$ magnesium nitrate precursor, and film thickness increased with increasing magnesium nitrate, resulting in thick coverage at higher concentrations (Figure 5). The degree of $\mathrm{MgO}$ coverage for blue and green phosphors was proportional to the amount of precursor.

CL performance. Coating effects on relative CL intensities

Table 1. Element compositions (wt \%) of metal oxide(M)-coated phosphors from EDS analysis

\begin{tabular}{ccccccccc}
\hline & \multicolumn{2}{c}{$\mathrm{SiO}_{2}$} & & \multicolumn{2}{c}{$\mathrm{Al}_{2} \mathrm{O}_{3}$} & & \multicolumn{2}{c}{$\mathrm{MgO}$} \\
\cline { 2 - 3 } \cline { 7 - 8 } \cline { 7 - 8 } & blue & green & & blue & green & & blue & green \\
\hline $\mathrm{O}$ & 30.8 & 25.5 & & 16.0 & 6.4 & & 8.6 & 10.1 \\
$\mathrm{M}$ & 6.3 & 7.3 & & 7.0 & 2.6 & & 3.8 & 6.0 \\
$\mathrm{~S}$ & 17.0 & 19.3 & & 24.9 & 38.8 & & 27.6 & 26.0 \\
$\mathrm{Zn}$ & 43.9 & 48.0 & & 52.0 & 52.3 & & 60.0 & 57.9 \\
\hline
\end{tabular}

for both blue and green coated phosphors were investigated at an accelerating voltage of $12 \mathrm{kV}, 1.6 \mu \mathrm{A} \mathrm{cm}{ }^{-2}$. As shown in Figure 6, the CL intensities of the coated phosphors decreased with increasing precursor concentration. Metal oxides may act as insulators, impeding electron beam penetration into the semi-

(a)
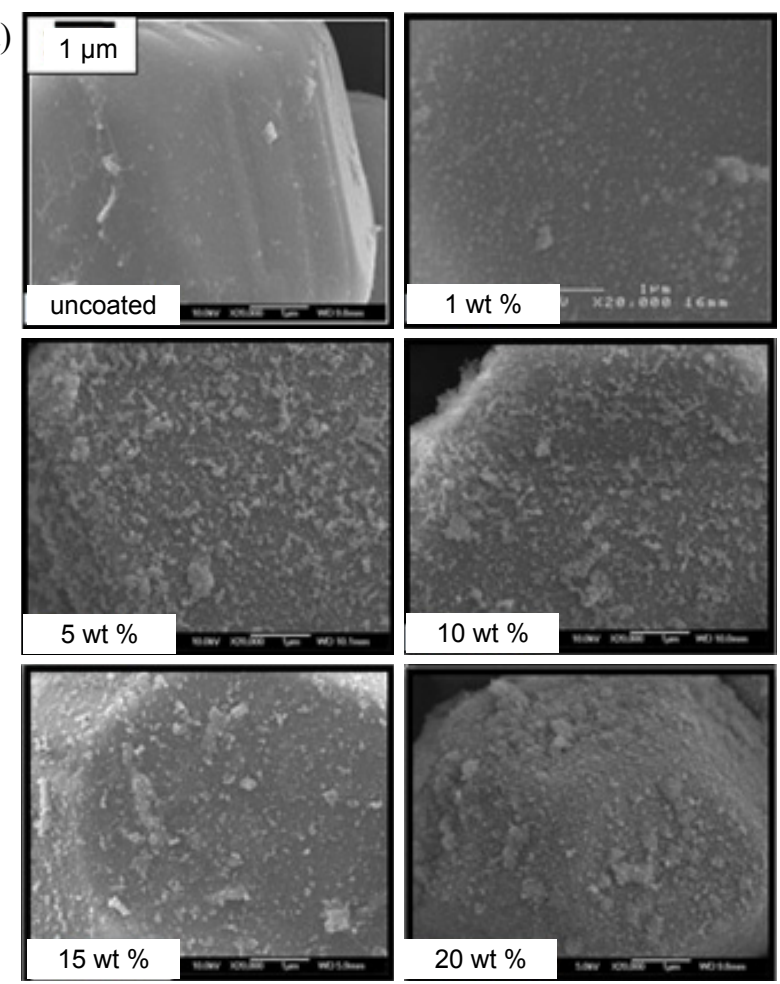

(b)
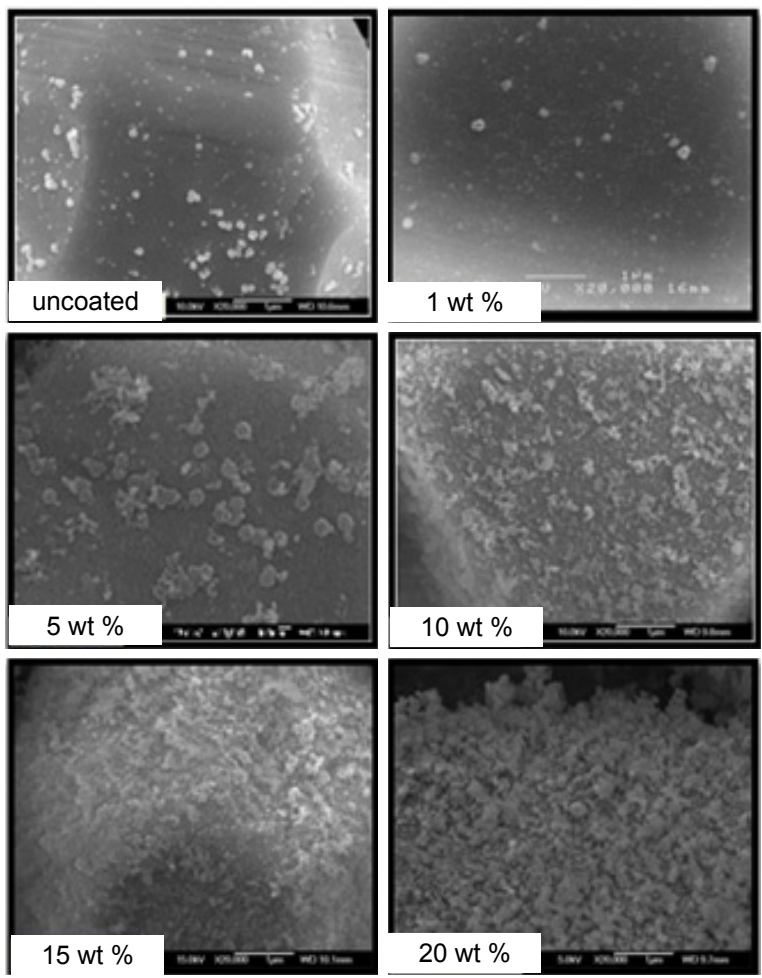

Figure 1. FE-SEM images of uncoated and $\mathrm{SiO}_{2}$-coated blue (a) and green (b) phosphors treated with various concentrations of the tetraethoxysilane precursor. 


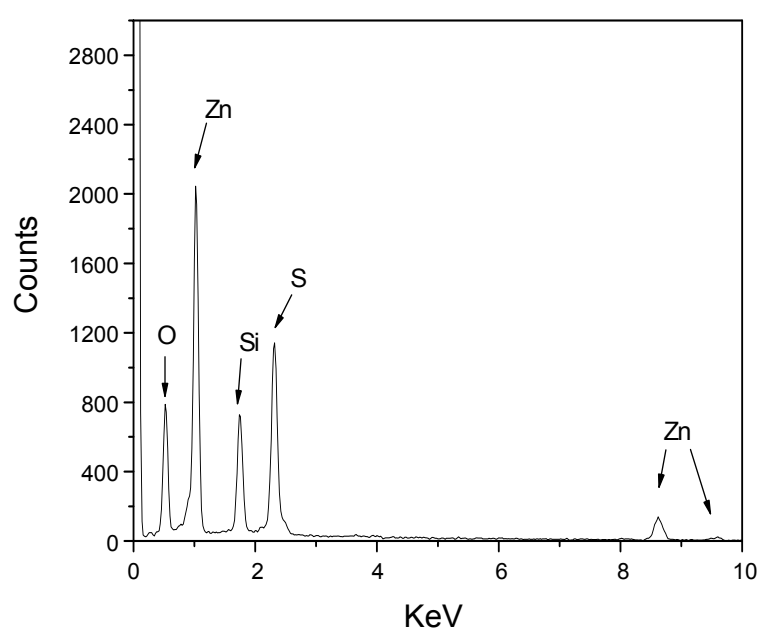

(a)
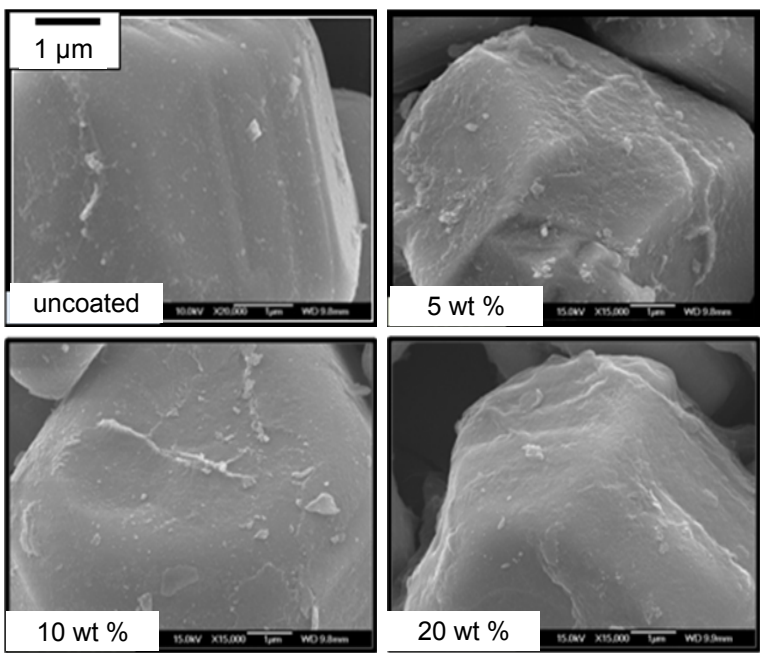

Figure 2. EDS spectrum of $\mathrm{SiO}_{2}$-coated blue phosphor.

(a)
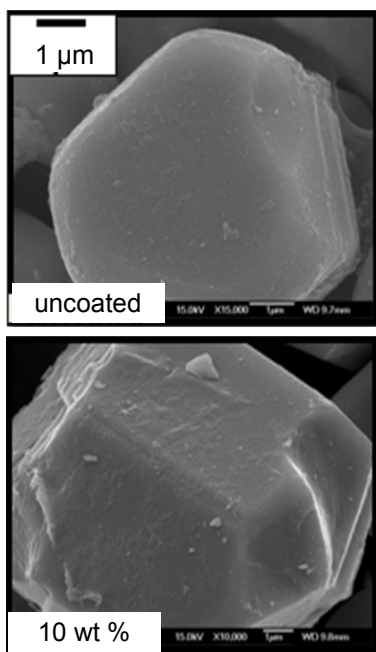

(b)
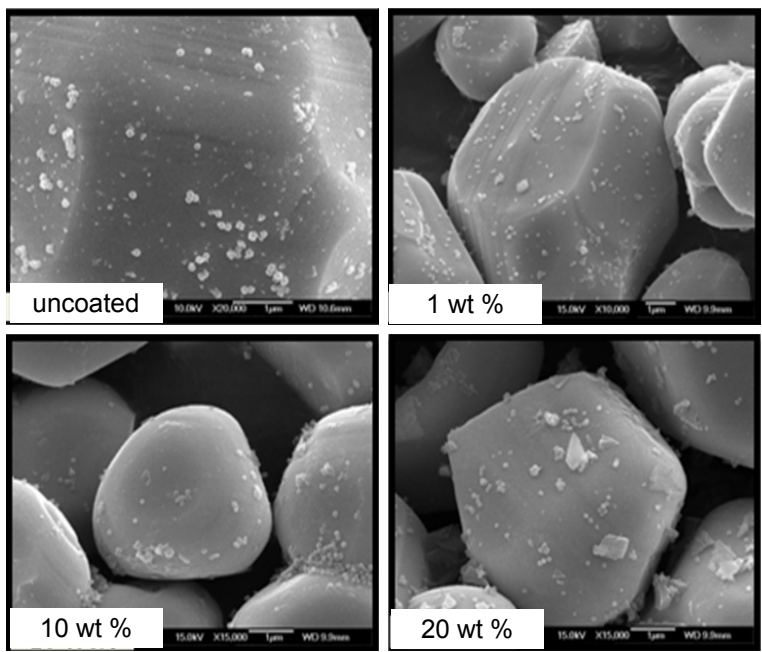

Figure 3. FE-SEM images of uncoated and $\mathrm{Al}_{2} \mathrm{O}_{3}$-coated blue (a) and green (b) phosphors treated with various concentrations of the aluminum nitrate presursor. (b)
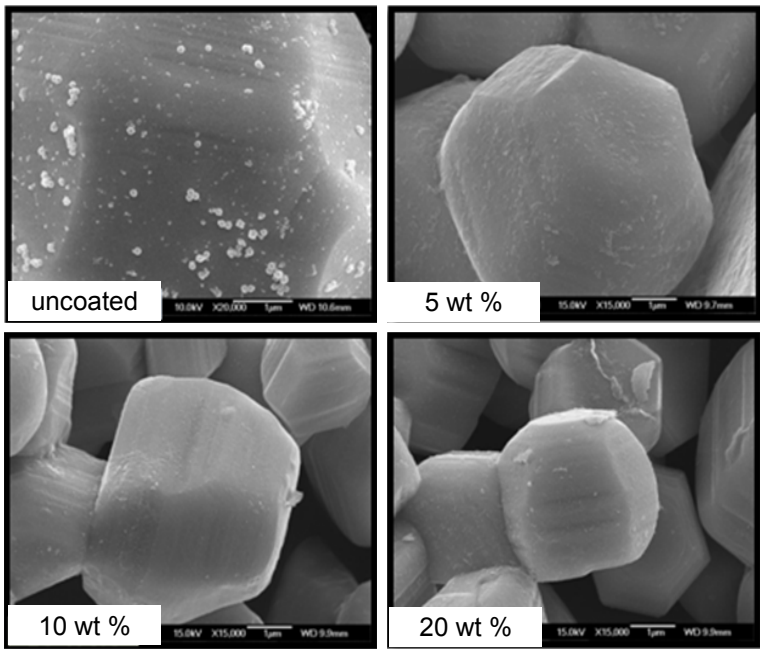

Figure 4. FE-SEM images of uncoated and $\mathrm{Al}_{2} \mathrm{O}_{3}$-coated blue (a) and green (b) phosphors treated with various concentrations of the aluminum isopropoxide precursor.

conductor phosphors, resulting in reduced CL intensity. $\mathrm{SiO}_{2}$ nanoparticle coatings resulted in the greatest CL intensity reductions, almost $20 \%$ for the $20 \mathrm{wt} \%$ TEOS solution. Morphologically, the $\mathrm{SiO}_{2}$ coated onto phosphor surfaces were nanoparticles instead of thin films; nanoparticles might produce a more diffused reflection of the incident beams than would a thin film.

Aging degradation of the uncoated was evaluated by measuring the loss of CL intensity with time under high-energy electron bombardment (Figure 7). For uncoated blue and green phosphors, CL intensity decreased by approximately $30 \%$ after 1000 s. For $\mathrm{SiO}_{2}$-coated blue phosphors, aging degradation decreased with increasing precursor concentration. Although blue phosphor surfaces were completely coated by $\mathrm{SiO}_{2}$ using a $20 \mathrm{wt} \%$ TEOS solution, CL intensity decreased by about $10 \%$ after $1200 \mathrm{~s}$. $\mathrm{SiO}_{2}$ coatings were more effective at reducing aging degradation in green phosphor. Green phosphor surfaces with 15 and $20 \mathrm{wt} \%$ precursor concentrations maintained initial CL intensity, with only minor fluctuation, for $1500 \mathrm{~s}$. The diffe- 
(a)
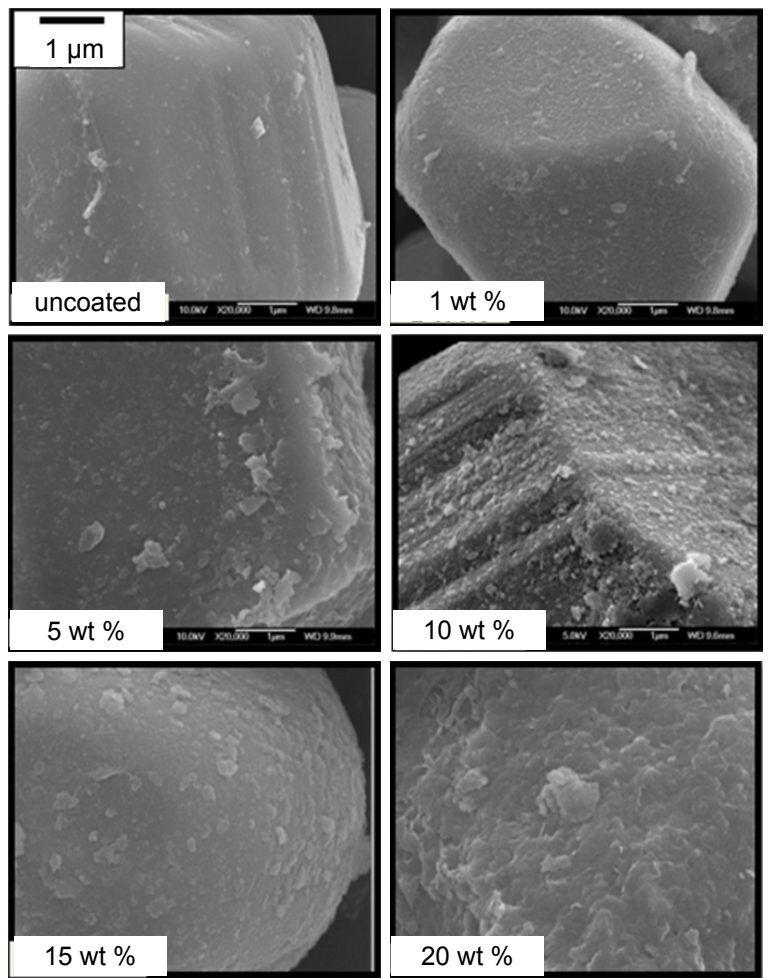

(b)
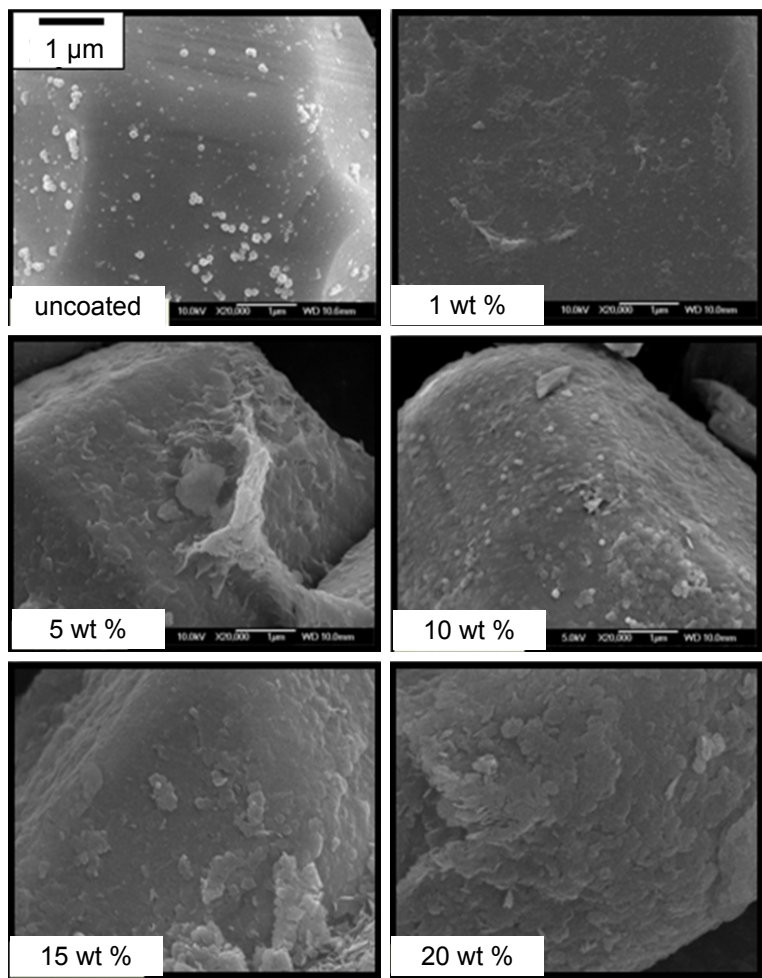

Figure 5. FE-SEM images of uncoated and MgO-coated blue (a) and green (b) phosphors treated with various concentrations of the magnesium nitrate precursor.

rence in the aging behaviors between the blue and the green phosphors can be attributed to the nature of dopants in the phosphors, since the host materials of both is zinc sulfide. The blue phosphor contains $\mathrm{Ag}, \mathrm{Al}$ and $\mathrm{Cl}$ ions as dopants, and the green

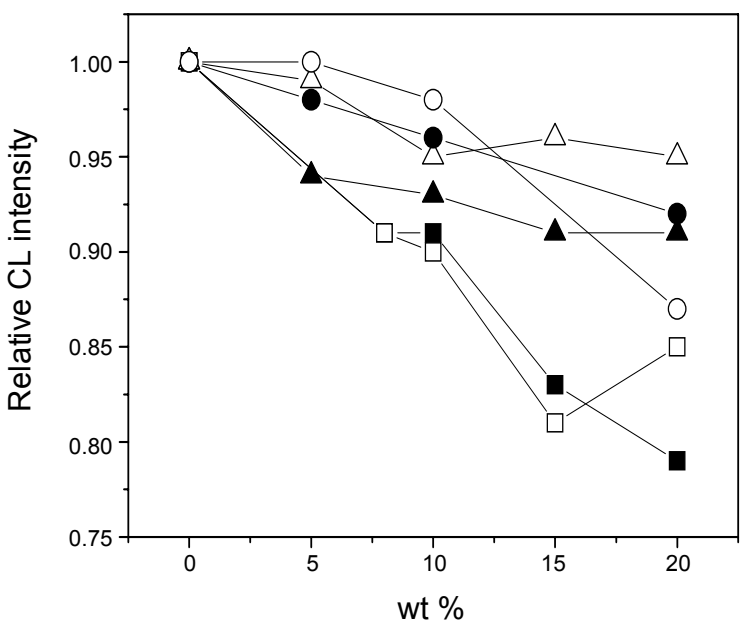

Figure 6. Relative CL intensities of coated blue (solid symbols) and green (open symbols) phosphors excited at $12 \mathrm{kV}, 1.6 \mu \mathrm{Acm}^{-2}$ (squares: $\mathrm{SiO}_{2}$, triangles: $\mathrm{Al}_{2} \mathrm{O}_{3}$, circles: $\mathrm{MgO}$ ).
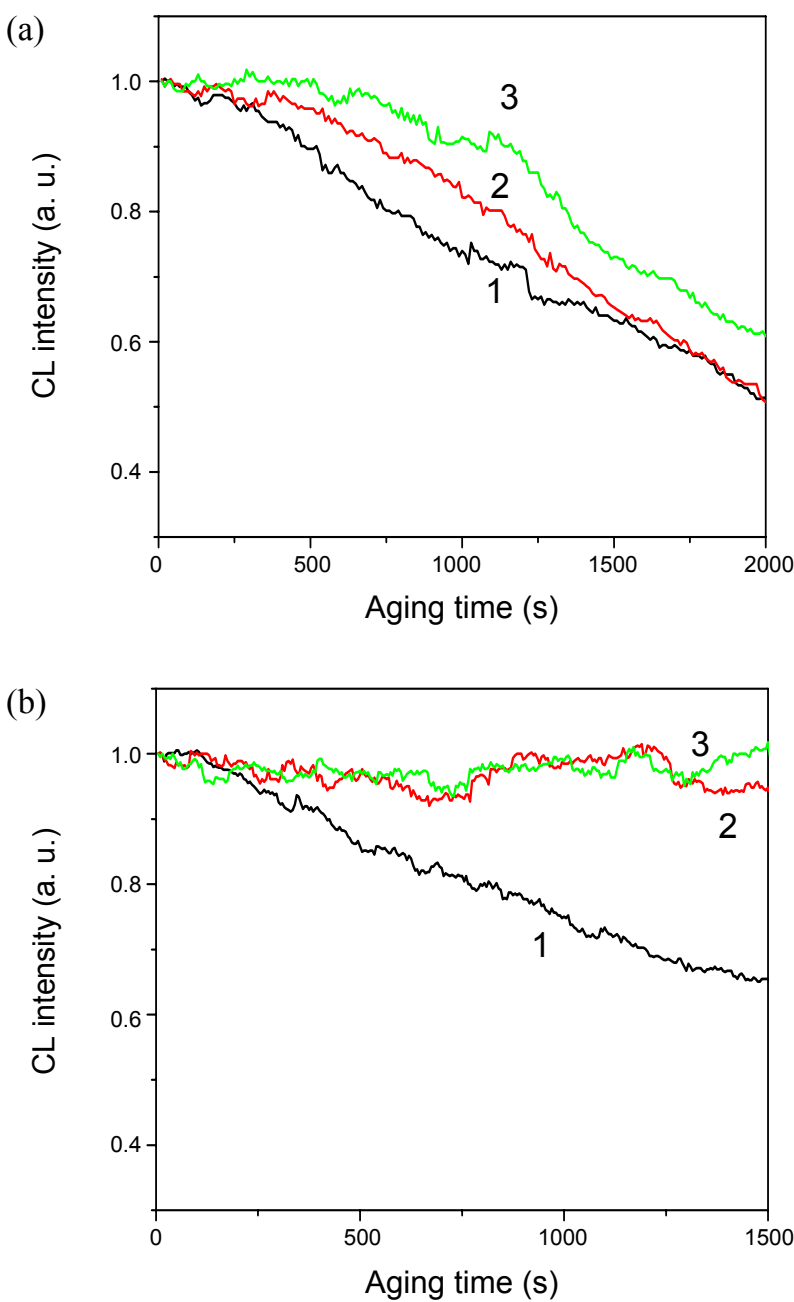

Figure 7. Aging behavior of uncoated and $\mathrm{SiO}_{2}$-coated blue (a) and green (b) phosphors treated with various concentrations of the tetraethoxysilane precursor (1: uncoated, 2: $10 \mathrm{wt} \%, 3: 20 \mathrm{wt} \%$ ). Accelerating voltage was $12 \mathrm{kV}$ and $1.6 \mu \mathrm{A} \mathrm{cm}^{-2}$. 
(a)

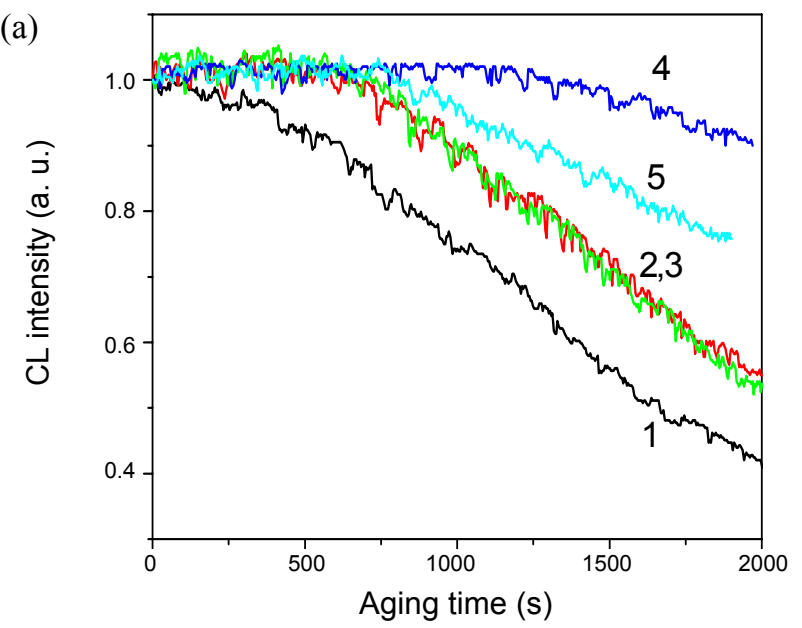

(b)

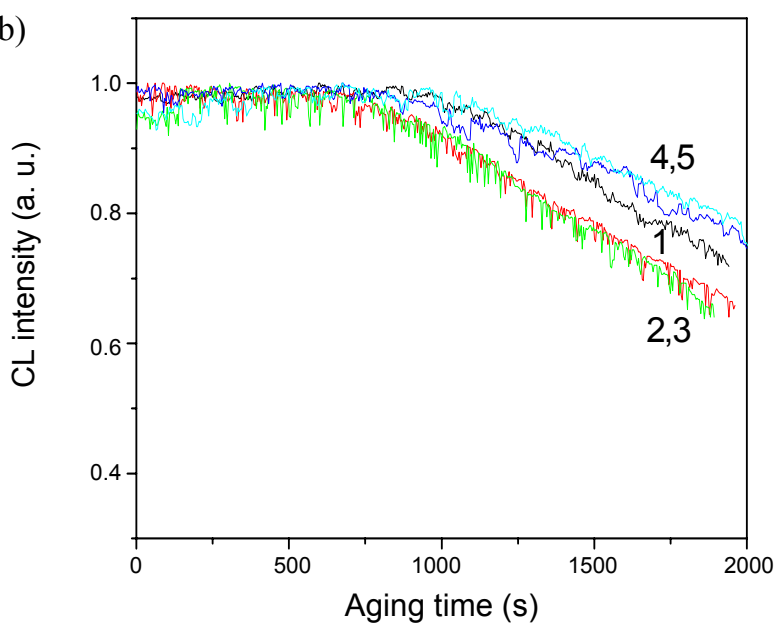

Figure 8. Aging behavior of uncoated and $\mathrm{Al}_{2} \mathrm{O}_{3}$-coated blue (a) and green (b) phosphors treated with various concentrations of the aluminum isopropoxide precursor (1: uncoated, $2: 5 \mathrm{wt} \%, 3 ; 10 \mathrm{wt} \%, 4: 15 \mathrm{wt} \%, 5: 20 \mathrm{wt} \%$ ). Accelerating voltage was $12 \mathrm{kV}$ and $1.6 \mu \mathrm{A} \mathrm{cm}$.
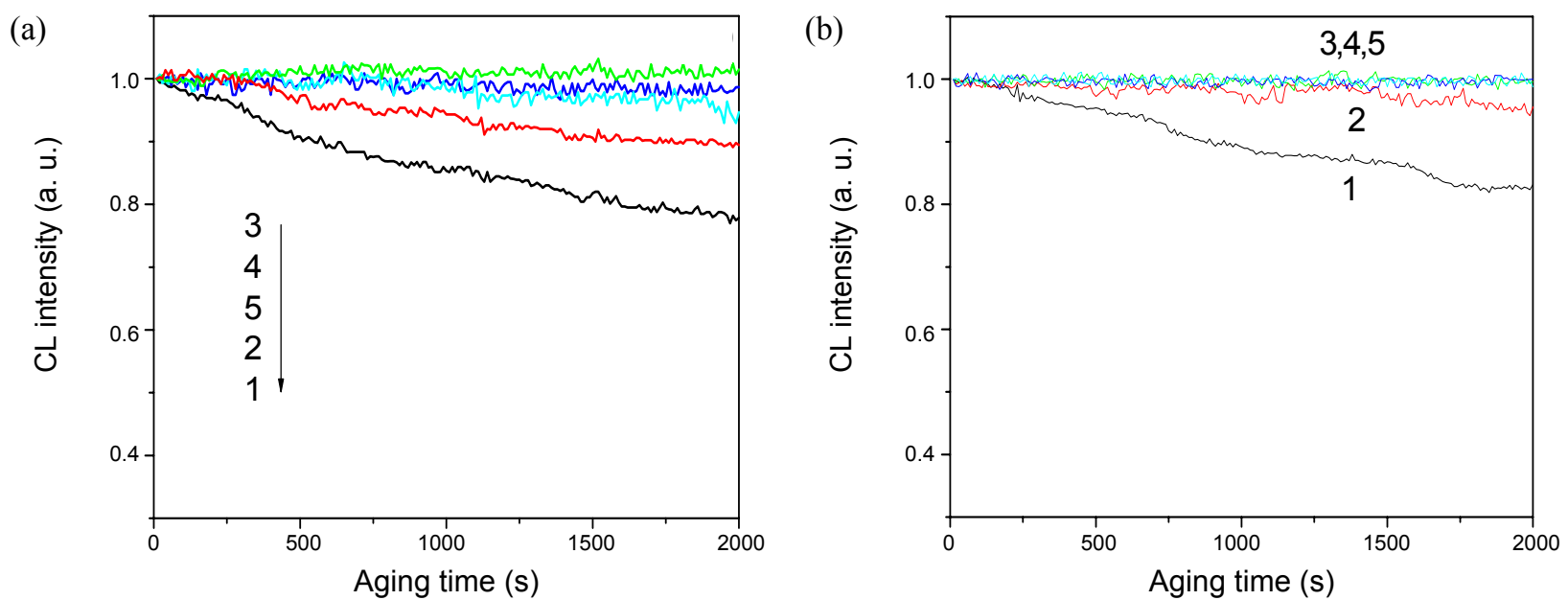

Figure 9. Aging behavior of uncoated and MgO-coated blue (a) and green (b) phosphors treated with various concentrations of the magnesium nitrate precursor (1: uncoated, 2: $5 \mathrm{wt} \%, 3 ; 10 \mathrm{wt} \%, 4: 15 \mathrm{wt} \%, 5: 20 \mathrm{wt} \%$ ). Accelerating voltage was $12 \mathrm{kV}$ and $1.6 \mu \mathrm{A} \mathrm{cm}$.

(a)

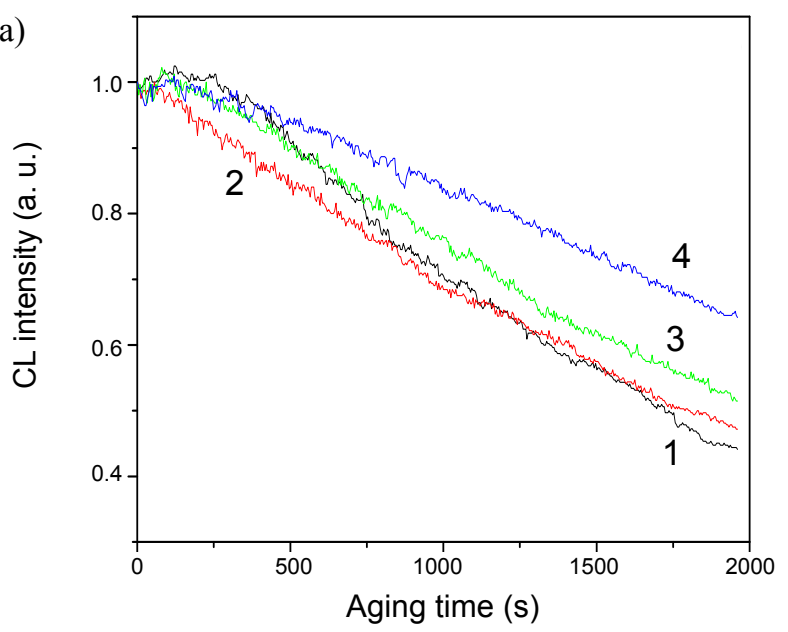

(b)

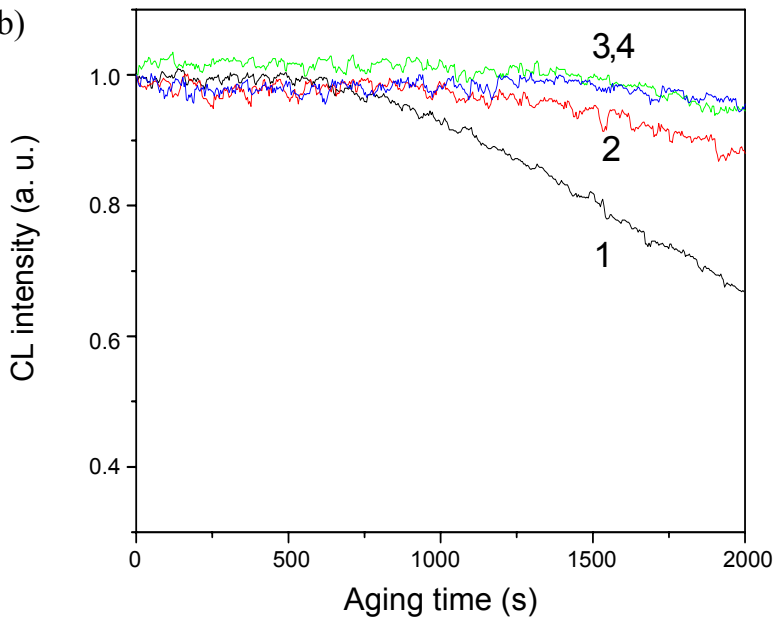

Figure 10. Aging behavior of uncoated and $\mathrm{MgO}$-coated blue (a) and green (b) phosphors treated with various concentrations of the magnesium nitrate precursor (1: uncoated, $2: 5 \mathrm{wt} \%, 3 ; 10 \mathrm{wt} \%, 4: 20 \mathrm{wt} \%$ ). Accelerating voltage was $15 \mathrm{kV}$ and $1.6 \mu \mathrm{A} \mathrm{cm}$. 

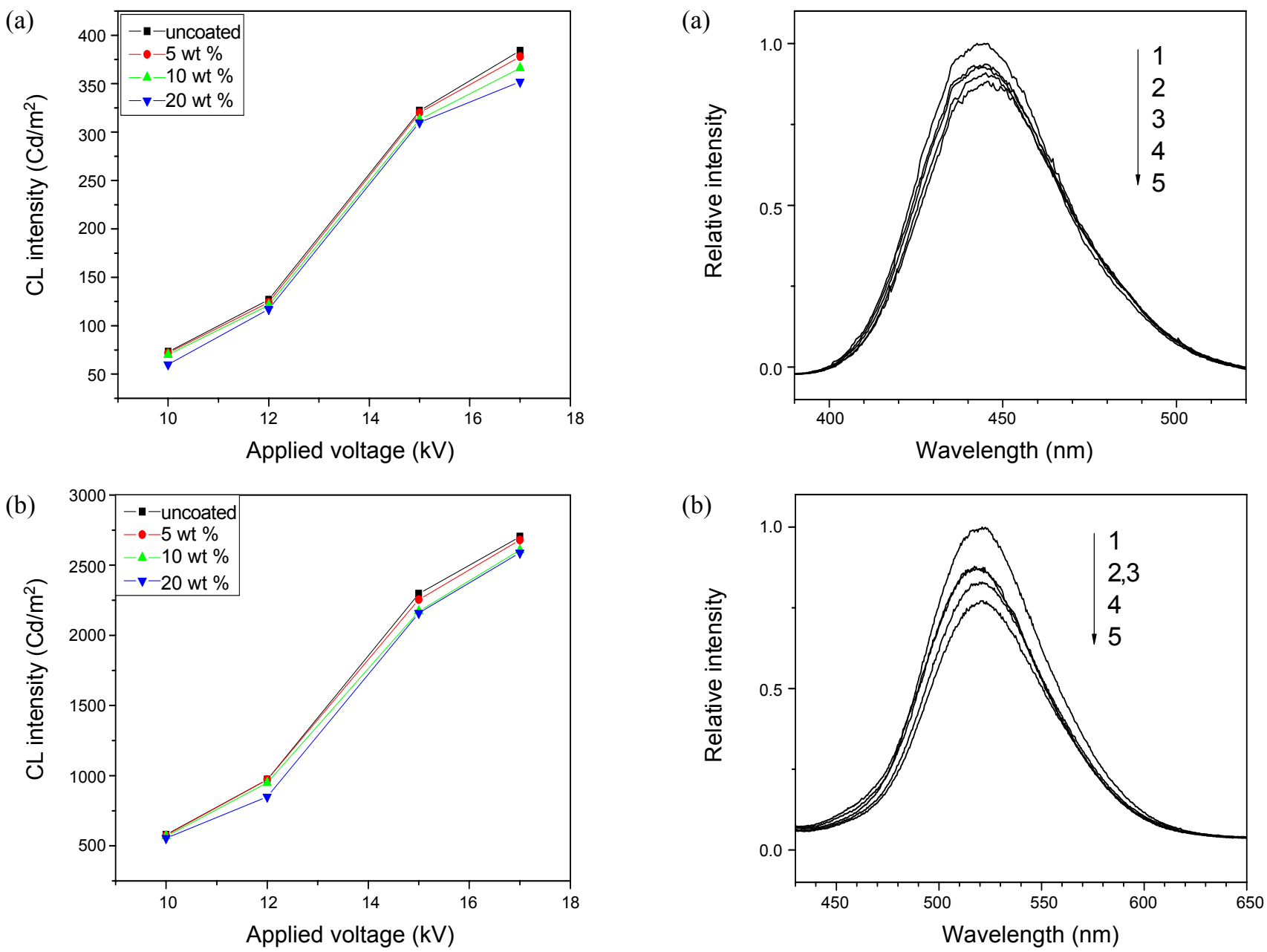

Figure 11. CL intensities of uncoated and $\mathrm{MgO}$-coated blue (a) and green (b) phosphors measured in the high voltage range of 10 to $17 \mathrm{kV}$.

Table 2. Chromaticity index (x, y) of uncoated and MgO-coated phosphors (applied voltage: $12 \mathrm{kV}$ )

\begin{tabular}{ccc}
\hline & blue & green \\
\hline uncoated & $0.1425,0.0465$ & $0.2994,0.5895$ \\
$5 \mathrm{wt} \%$ & $0.1421,0.0504$ & $0.2916,0.5963$ \\
10 & $0.1424,0.0511$ & $0.2945,0.5969$ \\
15 & $0.1433,0.0508$ & $0.2955,0.5981$ \\
20 & $0.1435,0.0519$ & $0.2964,0.6004$ \\
\hline
\end{tabular}

phosphor contains $\mathrm{Cu}$ and $\mathrm{Al}$ ions as dopants. By the excitation of the high-voltage electron beam, the light $\mathrm{Cl}$ ion with a negative charge is more affected than the heavy metal ions with positive charges. The $\mathrm{Cl}$ ion may result in the blue phosphor less stable.

Aging properties of $\mathrm{Al}_{2} \mathrm{O}_{3}$ film-coated phosphors using the AI precursor were measured (Figure 8), but due to poor coating of blue phosphors, those prepared using the AN precursor were not analyzed. Even though both blue and green phosphor surfaces were completely covered by a very uniform and thin $\mathrm{Al}_{2} \mathrm{O}_{3}$ film, aging degradation occurred rapidly, regardless of the precursor concentration.

Figure 12. PL spectra of uncoated and MgO-coated blue $\left(\lambda_{\text {exn }}=368 \mathrm{~nm}\right)$ (a) and green $\left(\lambda_{\text {exn }}=410 \mathrm{~nm}\right)$ (b) phosphors.

The $\mathrm{MgO}$ coating effectively protected both blue and green phosphors from aging degradation (Figure 9). For blue phosphors treated with a $5 \mathrm{wt} \%$ precursor concentration, CL intensity decreased only about $10 \%$ after 2000 s. At greater precursor concentrations, CL intensity remained very stable for $2000 \mathrm{~s}$. $\mathrm{MgO}$-coated green phosphors treated with a $5 \mathrm{wt} \%$ precursor concentration experienced only a $5 \mathrm{wt} \%$ degradation after $2000 \mathrm{~s}$. The optimum concentration of magnesium nitrate precursor was $10 \mathrm{wt} \%$ for both blue and green phosphors (Figure 9), experiencing only a $3 \%$ reduction in initial CL intensity due to $\mathrm{MgO}$ coating. Aging degradation of $\mathrm{MgO}$-coated blue phosphors degraded quickly when irradiated with a $15 \mathrm{kV}(1.6 \mu \mathrm{A}$ $\mathrm{cm}^{-2}$ ) accelerating electron beam (Figure 10). In contrast, $\mathrm{MgO}-$ coated green phosphors maintained initial CL intensity for approximately $1200 \mathrm{~s}$, followed by a very slight aging degradation after $2000 \mathrm{~s}$. Thus, critical voltage was below $15 \mathrm{kV}$ for MgOcoated blue and green phosphors.

The metal oxide coating materials act as insulators, and the band gaps of $\mathrm{SiO}_{2}, \alpha-\mathrm{Al}_{2} \mathrm{O}_{3}$ and $\mathrm{MgO}$ were 9.0, 8.8 and $8.7 \mathrm{eV}$, respectively. ${ }^{23,24}$ Insulator coatings may build up charge potential on the surface and result in an additional CL intensity reduction. CL intensity of uncoated and $\mathrm{MgO}$-coated phosphors 
was investigated as a function of applied electron-beam voltage in the $10-17 \mathrm{kV}$ range. As shown in Figure 11, CL intensity of uncoated and $\mathrm{MgO}$-coated phosphors gradually increased with increasing voltage, and slopes for coated phosphors were parallel to those of uncoated phosphors. The CL intensities of the $10 \mathrm{wt} \% \mathrm{MgO}$-coated blue and green phosphors were evaluated as $45.6( \pm 5.5)$ and $309.1( \pm 30.1) \mathrm{Cd} \mathrm{m}^{-2} \mathrm{kV}^{-1}$, respectively. As listed in Table 2, the CIE 1931 chromaticity of the phosphors was almost unaffected by $\mathrm{MgO}$ coating. The scaletype $\mathrm{MgO}$-coating effect on the CL intensity is extraordinary, compared with the case for the PL intensity. As shown in Figure 12, the PL intensity of the coated phosphor apparently decreased with increasing the amount of the precursor. These indicate that no extra energy loss occurred due to insulatorrelated, built-up charge potential on the phosphor surface.

\section{Conclusion}

Relatively simple methods were used to coat blue P22B and green P22G phosphors. Hydrolysis of tetraethoxysilane, aluminum isopropoxide, and magnesium nitrate precursors, with subsequent heat annealing, produced $\mathrm{SiO}_{2}$ nanoparticles, an $\mathrm{Al}_{2} \mathrm{O}_{3}$ thin film, and $\mathrm{MgO}$ scale-type films, respectively, on phosphor surfaces. At $12 \mathrm{kV}$, the $\mathrm{Al}_{2} \mathrm{O}_{3}$ thin film and $\mathrm{MgO}$ films resulted in less decrease in CL intensity as compared with $\mathrm{SiO}_{2}$ nanoparticles. This can be attributed to greater incident beam diffraction by $\mathrm{SiO}_{2}$ nanoparticles. Aging degradation of uncoated phosphors during excitation at $12 \mathrm{kV}$ was profound, with a decrease in CL intensity of about $20 \%$ after $2000 \mathrm{~s}$, presumably due to degradation of the uncoated phosphors under high-energy electron bombardment. Significant aging degradation occurred in all concentrations of the $\mathrm{SiO}_{2}$-coated blue phosphor and the $\mathrm{Al}_{2} \mathrm{O}_{3}$-coated blue and green phosphors. The $\mathrm{MgO}$ multilayered films were most effective for reducing aging degradation. Blue and green phosphors treated with a $10 \mathrm{wt} \%$ (or greater) magnesium nitrate solution maintained their initial CL intensities for $2000 \mathrm{~s}$.

Acknowledgments. This study was supported by a grant from Korea Energy Management Corporation (Project No.: 2006ECM12P07).

\section{References}

1. Holloway, P. H.; Trottier, T. A.; Sebastian, J.; Jones, S.; Zhabg, X.-M.; Bang, J.-S.; Abrams, B.; Thomes, W. J.; Kim, T.-J. J. Appl. Phys. 2000, 88, 483.

2. Swart, H. C.; Hillie, K. T. Surf. Interface Anal. 2000, 30, 383.

3. Villalobos, G. R.; Bayya, S. S.; Sanghera, J. S.; Miklos, R. E.; Kung, F.; Aggarwal, I. D. J. Am. Ceram. Soc. 2000, 85, 2128.

4. Park, W.; Wagner, B. K.; Russell, G.; Yasuda, K.; Summers, C. J.; Do, Y. R.; Yang, H. G. J. Mater. Res. 2000, 15, 2288.

5. Lee, R. Y.; Kim, S. W. J. Lumin. 2001, 93, 93.

6. Choi, A.-W.; Hong, S.-H. J. Am. Ceram. Soc. 2008, 91, 451.

7. Kominami, H.; Nakamura, T.; Sowa, K.; Nakanishi, Y.; Hatanaka, Y.; Shimaoka, G. Appl. Surface Sci. 1997, 113/114, 519.

8. Chang, C.-H.; Chiou, B.-S.; Chen, K.-S.; Ho, J.-C. Appl. Surface Sci. 2005, 243, 55.

9. Souriau, J.-C.; Jiang, Y. D.; Penczek, J.; Paris, H. G.; Summers, C. J. Mater. Sci. Eng. B 2000, 76, 165.

10. Guo, C.; Chu, B.; Su, Q. Appl. Surface Sci. 2004, 225, 198.

11. Jung, S. M.; Jung, H. Y.; Suh, J. S. Carbon 2008, 46, 1973.

12. Wu, J.; Wyse, M.; McClain, D.; Thomas, N.; Jiao, J. Nano Lett. 2009, 9, 595 .

13. Pan, J.-Y.; Chen, C.-Y; Gao, Y.-L.; Zhu, C.-C. Displays 2009, 30, 114.

14. Kim, K. S.; Ryu, J. H.; Lee, C. S.; Jang, J.; Park, K. C. J. Mater. Sci: Mater Electron 2009, 20, S120.

15. Shiratori, Y.; Sugime, H.; Noda, S. J. Phys. Chem C 2008, 112, 17974.

16. Stratakis, E.; Kymakis, E.; Spanakis, E.; Tzanetakis, P.; Koudoumasb, E. Phys. Chem. Chem. Phys. 2009, 11, 703.

17. Huang, J. X.; Chen, J.; Deng, S. Z.; She, J. C.; Xua, N. S. J. Vac. Sci. Technol. B 2008, 26, 1700.

18. Cho, W.-S.; Lee, H.-J.; Lee, Y.-D.; Park, J.-H.; Kim, J.-K.; Lee, Y.-H.; Ju, B.-K. IEEE. Electron Device Lett. 2007, 28, 386.

19. Jung, Y. J.; Son, G. H.; Park, J. H.; Kim, Y. W.; Berdinsky, A. S.; Yoo, J. B.; Park, C. Y. Diamond Relat. Mater. 2005, 14, 2109.

20. Ko, K.-Y.; Huh, Y.-D.; Do, Y. R. Bull. Korean Chem. Soc. 2008 , $29,822$.

21. Jeong, J.-W.; Kim, D.-J.; Cho, K.-I.; Song, Y.-H. J. Vacuum Sci. Tech. B 2009, 27, 1097.

22. Kao, C.-C.; Liu, Y.-C. Mater. Chem. Phys. 2009, 115, 463.

23. Demkov, A. A.; Fonseca, L. R. C.; Verret, E.; Tomfohr, J.; Sankey, O. F. Phys. Rev. B 2005, 71, 195306.

24. King, P. D. C.; Veal, T. D.; Schleife, A.; Zúñiga-Pérez, J.; Martel, B.; Jefferson, P. H.; Fuchs, F.; Muñoz-Sanjosé, V. Phys. Rev. B 2009, 79, 205205. 